\title{
Pediatric hydrocephalus: systematic literature review and evidence-based guidelines. Part 8: Management of cerebrospinal fluid shunt infection
}

\author{
Mandeep S. Tamber, M.D., Ph.D., ${ }^{1}$ Paul Klimo Jr., M.D., M.P.H., ${ }^{2,3}$ \\ Catherine A. Mazzola, M.D. ${ }^{4}$ And Ann Marie Flannery, M.D. ${ }^{5}$ \\ ${ }^{1}$ Department of Pediatric Neurological Surgery, Children's Hospital of Pittsburgh, University of Pittsburgh, \\ Pittsburgh, Pennsylvania; ${ }^{2}$ Department of Neurosurgery, University of Tennessee Health Science Center, \\ Memphis, and ${ }^{3}$ Le Bonheur Children's Hospital, Memphis, Tennessee; ${ }^{4}$ Division of Pediatric Neurological \\ Surgery, Goryeb Children's Hospital, Morristown, New Jersey; and ${ }^{5}$ Department of Neurological Surgery, \\ Saint Louis University, St. Louis, Missouri
}

Object. The objective of this systematic review was to answer the following question: What is the optimal treatment strategy for CSF shunt infection in pediatric patients with hydrocephalus?

Methods. The US National Library of Medicine and the Cochrane Database of Systematic Reviews were queried using MeSH headings and key words relevant to the objective of this systematic review. Abstracts were reviewed, after which studies meeting the inclusion criteria were selected and graded according to their quality of evidence (Classes I-III). Evidentiary tables were constructed that summarized pertinent study results, and based on the quality of the literature, recommendations were made (Levels I-III).

Results. A review and critical appraisal of 27 studies that met the inclusion criteria allowed for a recommendation for supplementation of antibiotic treatment using partial (externalization) or complete shunt hardware removal, with a moderate degree of clinical certainty. However, a recommendation regarding whether complete shunt removal is favored over partial shunt removal (that is, externalization) could not be made owing to severe methodological deficiencies in the existing literature. There is insufficient evidence to recommend the use of intrathecal antibiotic therapy as an adjunct to systemic antibiotic therapy in the management of routine CSF shunt infections. This also holds true for other clinical scenarios such as when an infected CSF shunt cannot be completely removed, when a shunt must be removed and immediately replaced in the face of ongoing CSF infection, or when the setting is ventricular shunt infection caused by specific organisms (for example, gram-negative bacteria).

Conclusions. Supplementation of antibiotic treatment with partial (externalization) or complete shunt hardware removal are options in the management of CSF shunt infection. There is insufficient evidence to recommend either shunt externalization or complete shunt removal as the preferred surgical strategy for the management of CSF shunt infection. Therefore, clinical judgment is required. In addition, there is insufficient evidence to recommend the combination of intrathecal and systemic antibiotics for patients with CSF shunt infection when the infected shunt hardware cannot be fully removed, when the shunt must be removed and immediately replaced, or when the CSF shunt infection is caused by specific organisms. The potential neurotoxicity of intrathecal antibiotic therapy may limit its routine use.

RECOMMENDATION: Supplementation of antibiotic treatment with partial (externalization) or with complete shunt hardware removal is an option in the management of CSF shunt infection. STRENGTH OF ReCOMmENDATION: Level II, moderate degree of clinical certainty.

RECOMMENDATION: There is insufficient evidence to recommend either shunt externalization or complete shunt removal as a preferred surgical strategy for the management of CSF shunt infection. Therefore, clinical judgment is required. STRENGTH OF RECOMMENDATION: Level III, unclear degree of clinical certainty.

RECOMMENDATION: There is insufficient evidence to recommend the combination of intrathecal and systemic antibiotics for patients with CSF shunt infection in whom the infected shunt hardware cannot be fully removed or must be removed and immediately replaced, or when the CSF shunt infection is caused by specific organisms. The potential neurotoxicity of intrathecal antibiotic therapy may limit its routine use. STRENGTH OF RECOMMENDATION: Level III, unclear degree of clinical certainty.

(http://thejns.org/doi/abs/10.3171/2014.7.PEDS14328)

$\begin{aligned} & \text { Key Words } \\ & \text { evidence-based guidelines }\end{aligned}$ cerebrospinal fluid shunt $\bullet$ infection $\bullet$ therapy $\bullet \quad$ pediatrics $\bullet$

$\mathrm{C}$ EREBROSPINAL fluid shunt infection is one of the most common and serious complications of CSF shunt therapy. Infection admissions number ap-

Abbreviations used in this paper: $\mathrm{EVD}=$ external ventricular drain; VA = ventriculoatrial; VP = ventriculoperitoneal. proximately 2300 per year in the United States and, in aggregate, account for more than 50,000 hospital days. ${ }^{29}$ Total hospital charges related to the management of CSF shunt infection were nearly \$250 million in 2003 adjusted dollars. ${ }^{29}$

Within 24 months after insertion, infections complicate approximately $11 \%$ of initial CSF shunt placements. ${ }^{28}$ 
Despite the high incidence of this complication, the optimal management of CSF shunt infection has yet to be defined. The existing evidence regarding the management of CSF shunt infection is of poor methodological quality. As such, current management is dictated not by evidence, but rather by physician preference and other possibly relevant patient-level factors (for example, patient surgical risk, ventricle size, and complexity of the shunt system). It is not surprising that there is significant variation in CSF shunt infection treatment protocols between centers. ${ }^{35}$

The objective of this systematic review was to answer the following question: What is the optimal treatment strategy for CSF shunt infection in pediatric patients with hydrocephalus? The successful treatment of CSF shunt infection aims to cure the infection (that is, minimize the probability of reinfection or relapse) while maintaining functional CSF diversion and minimizing morbidity, mortality, and the cost of therapy. The alternative paradigms for the management of ventricular shunt infection are illustrated well if one considers important historical milestones in the treatment of hydrocephalus. The evidentiary tables are structured somewhat accordingly (Fig. 1). The development of the Holter-Pudenz valve in 1957 and the ability to insert the distal end of a ventricular shunt into the right atrium was a major development in the treatment of hydrocephalus. Although ventriculoatrial (VA) shunts facilitated continuous and regulated CSF diversion, the fact that the distal catheter entered the heart posed logistical problems when these shunts inevitably became infected. A major issue with VA shunts was loss of limited venous access if these shunts were removed and not immediately replaced. In light of this limitation, the predominance of literature examining the treatment of CSF shunt infections in the era of VA shunts documented the outcomes of treatment with systemic antibiotics alone (Table 1) and whether the elevated CSF antibiotic concentrations achieved by intrathecal therapy conferred any additional benefit in managing the ventriculitis that often accompanied CSF shunt infection-both while leaving the infected shunt in situ or after removing the shunt and immediately replacing it in infected cerebrospinal fluid (Table 2).

A decade later, Ames developed a technique for placement of the distal catheter in the peritoneal space, and as such, made shunt removal and later replacement a feasible surgical strategy in the management of CSF shunt infection. Over time, the combined medical and surgical treatment of ventricular shunt infection became more accepted, in part because of the gradual phase-out of VA shunts and their associated limitations with respect to repeated surgical access to the heart, but perhaps more significantly because of the realization that an infected ventricular shunt, as an infected foreign body, was difficult if not impossible to sterilize using antibiotics alone. This management philosophy accepts not only that shunt removal (and eventual replacement once CSF sterility is achieved) requires multiple surgeries, but also the risk of introducing secondary infection during a variable period of external drainage. Therefore, although more contemporary literature examining the treatment of CSF shunt infection consists of studies that incorporate some form of shunt removal, variations in whether the infected shunt was partially removed (that is, externalized) (Table 3 ) or completely removed (see Table 4), and whether supplemental intrathecal antibiotics were administered contribute to significant between-study heterogeneity.

A lack of rigorous comparative effectiveness studies leads to uncertainty regarding the preferred therapeutic strategy for a particular clinical circumstance. Decision analytical modeling attempts to apply statistical simulation techniques to preexisting data to rank competing therapeutic options in terms of their relative effectiveness. A decision analysis examining the treatment of CSF shunt infection using data from published studies (most included in evidentiary Tables 1-4) came to the conclusion that the best treatment modality for CSF shunt infection was antibiotic administration (systemic, with or without intrathecal administration) and complete removal

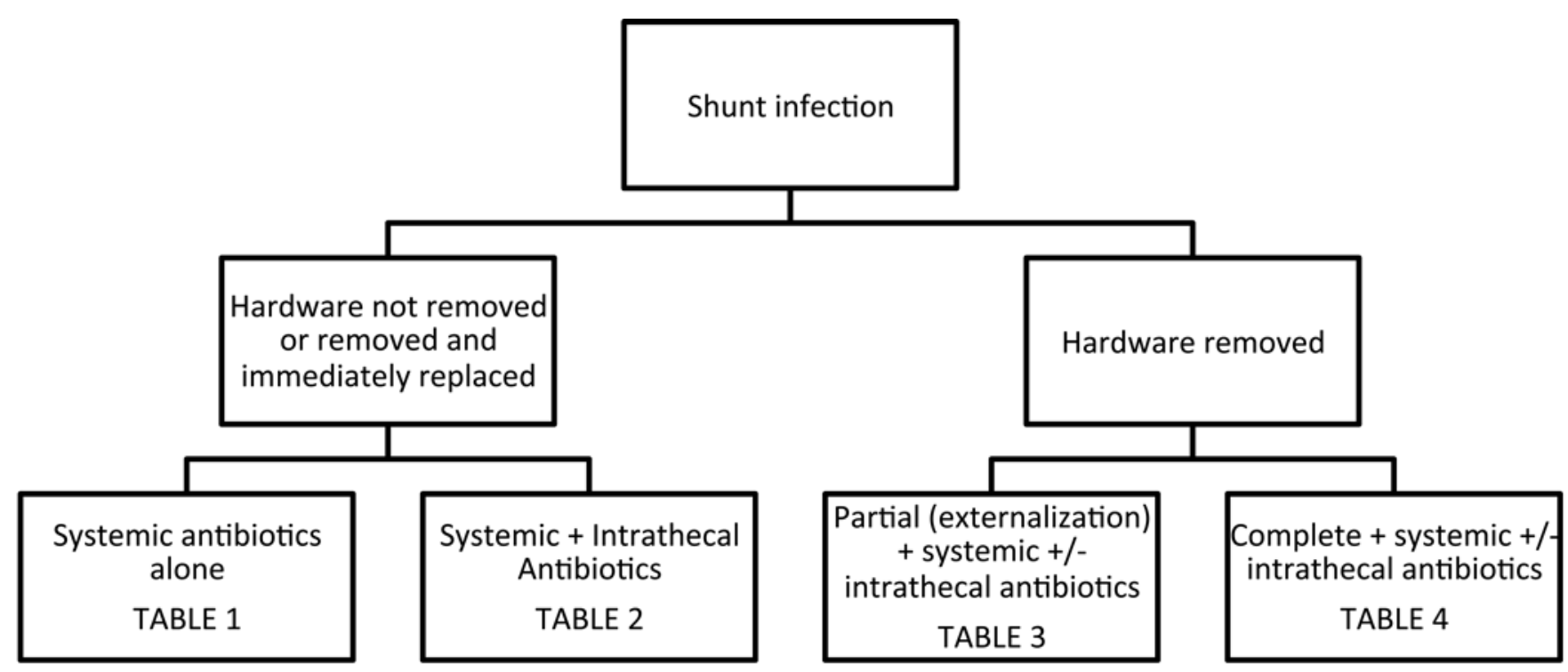

FIG. 1. Organization of evidentiary tables based on alternative paradigms for the management of CSF shunt infection. 
M. S. Tamber et al.

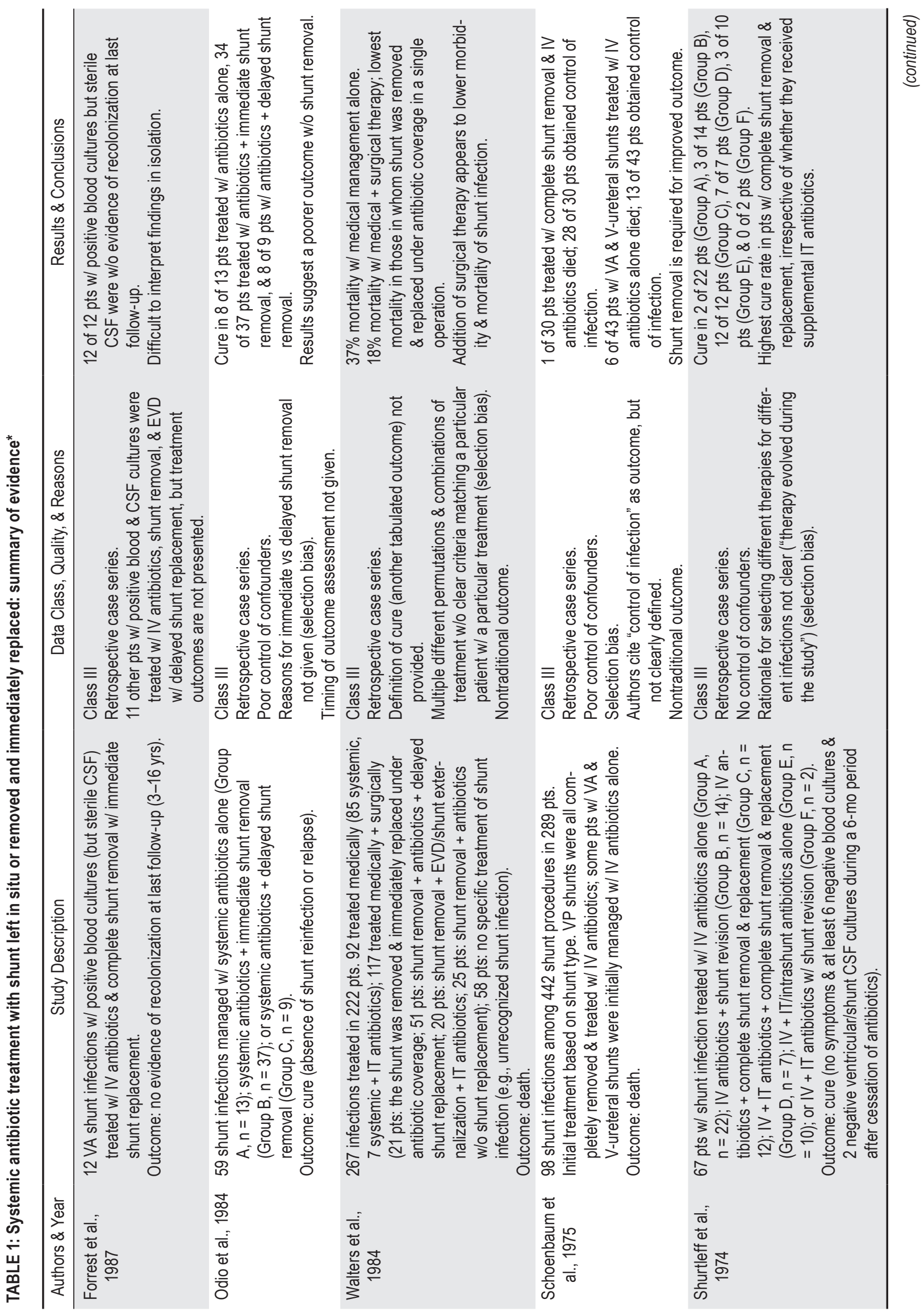




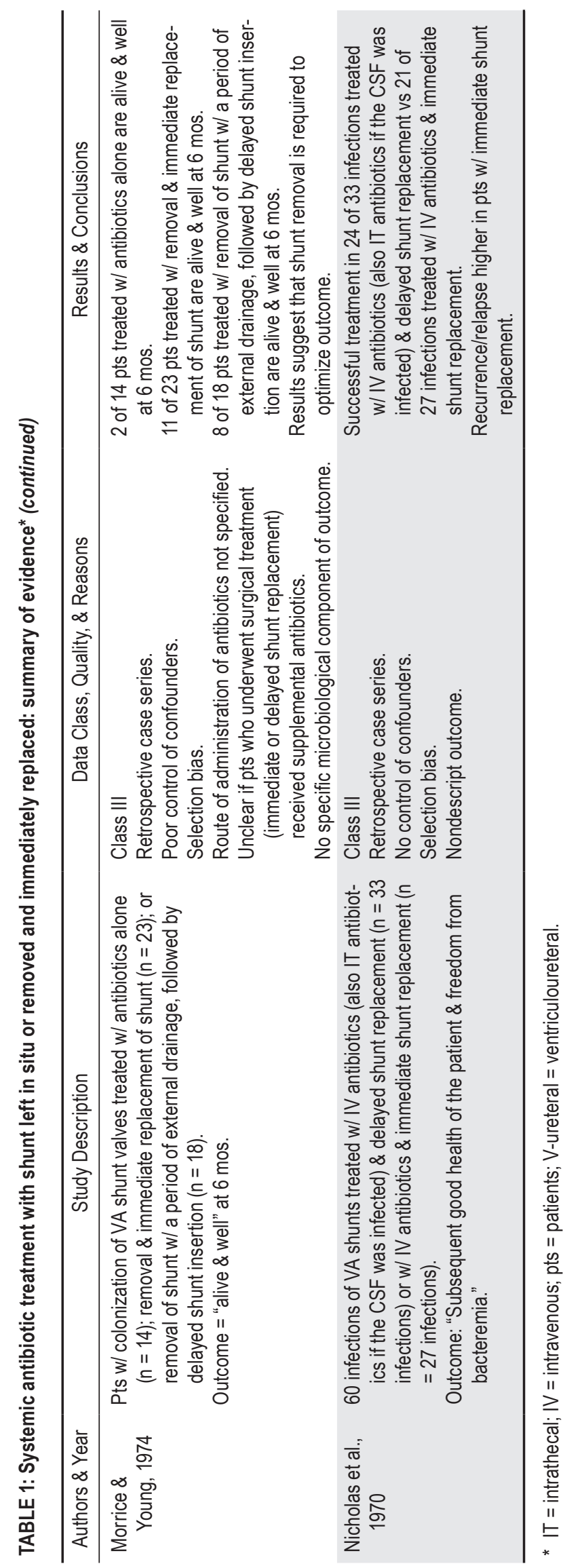

of the infected shunt, with intercurrent external ventricular drainage or ventricular taps, followed by placement of a new shunt when CSF sterility is achieved. Sensitivity analyses revealed that this treatment option had the highest cure rate, the lowest failure rate, and the lowest mortality rate when compared with treatment consisting of antibiotic therapy with shunt removal and immediate replacement, or antibiotic treatment alone, over a wide range of assumptions..$^{23}$

Multiple review articles on the topic also conclude that shunt infection should be ideally managed with antibiotics, complete shunt removal, and placement of a temporary external ventricular drain (EVD), followed by reimplantation after CSF sterilization., ${ }^{1,4,7,36,37}$ Although intrathecal administration of antibiotics appears to make theoretical sense because of enhanced CSF antibiotic concentrations, its practical application is controversial, owing in large part to the potential adverse effects of intrathecal therapy, including neurotoxicity. The indications for intrathecal therapy are not well established and presently range from use in any shunt infection, use in only those infections in which the CSF cannot be sterilized by systemic antibiotics alone (for example, persistent positive cultures), or use in those ventricular shunt infections caused by specific organisms (for example, gramnegative infections).

A practice survey of board-certified members of the American Society of Pediatric Neurosurgeons revealed that most surgeons treat ventricular shunt infection with antibiotics, removal of the infected CSF shunt, and placement of an EVD, followed by delayed shunt replacement-a management paradigm that can be supported by the available evidence, as detailed below. ${ }^{35}$

\section{Methods}

\section{Search Criteria}

We searched the US National Library of Medicine (PubMed/MEDLINE) database and the Cochrane Database of Systematic Reviews for the period January 1966 through March 2012 using the following MeSH subject headings: (CSF shunts) AND (bacterial infection OR prosthesis-related infection OR catheter-related infection) AND (treatment OR outcome) AND (antibacterial agents OR injections OR antibiotics OR device removal OR ventriculostomy OR combined modality therapy). Searches were limited to studies in patients younger than 18 years of age, the management of initial (not repeat) CSF shunt infection, and to the English language.

\section{Search Results}

A total of 342 abstracts were screened and 69 fulltext articles were retrieved for review. The details of this process are described in Part 1, the introduction and methodology section of these guidelines. ${ }^{5}$ An examination of the reference lists of these 69 full-text articles yielded an additional 24 articles that warranted full-text review (Fig. 2). Subsequent review of the full texts of these 93 articles led to the exclusion of 66 articles based on predefined criteria, leaving 27 articles as the basis for 
M. S. Tamber et al.

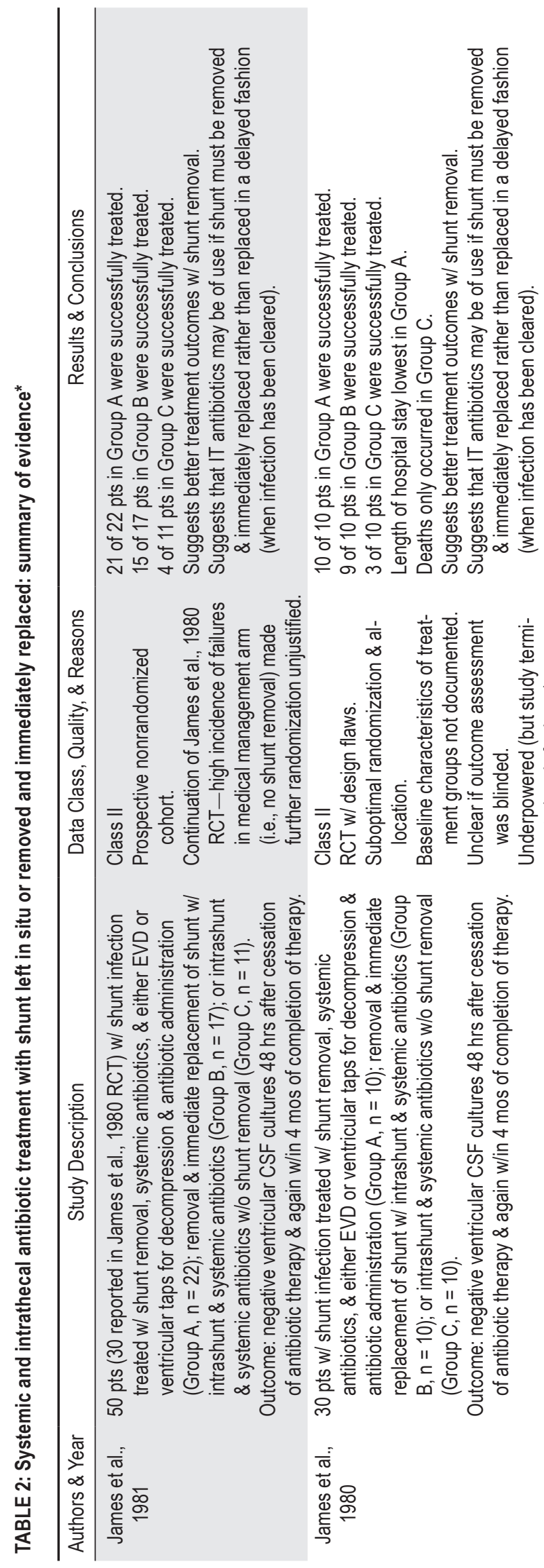

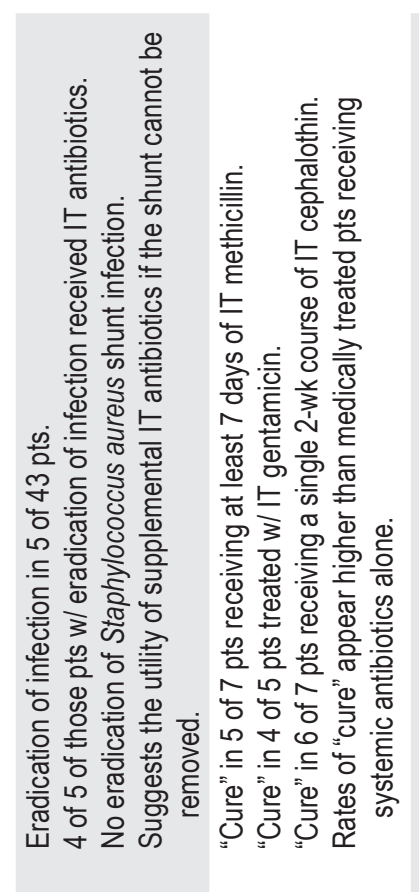

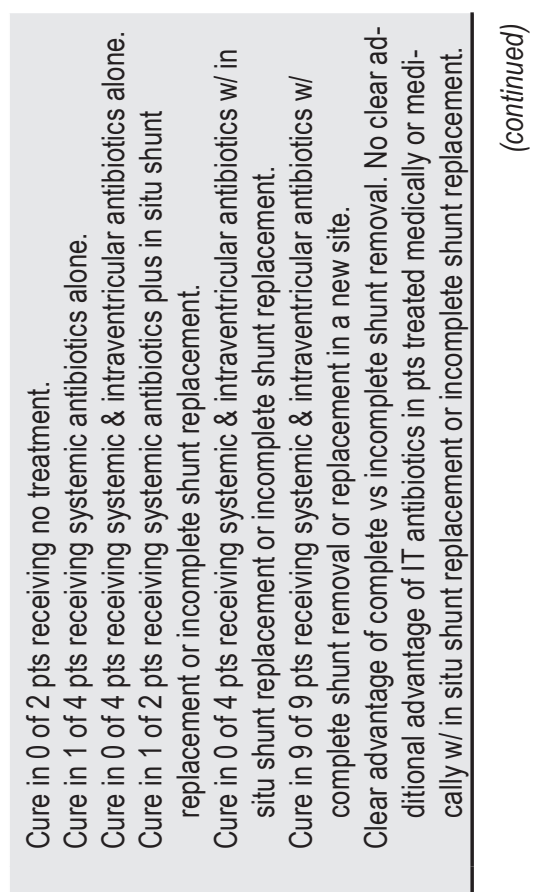




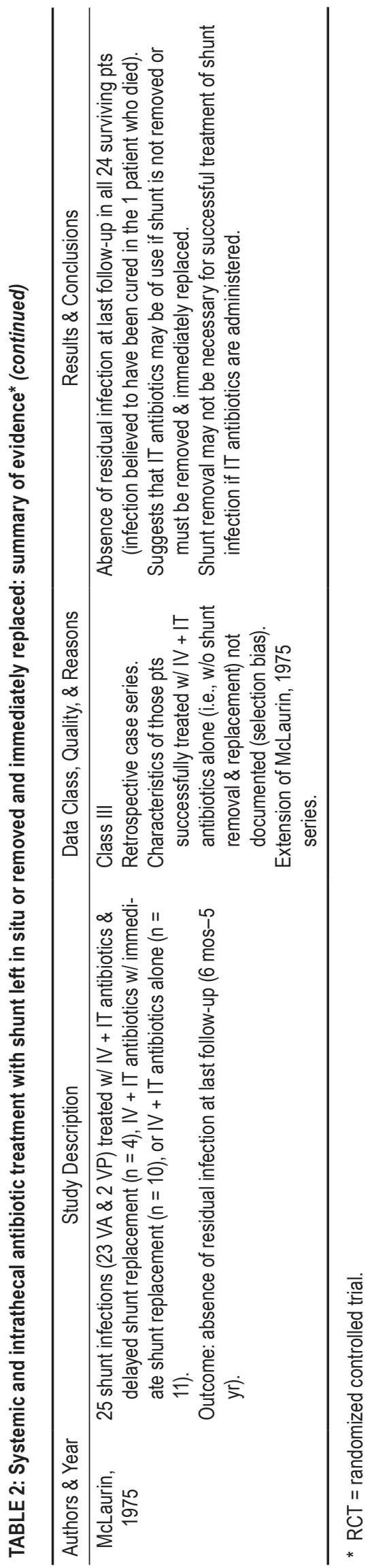

the evidentiary tables for this particular recommendation. Reasons for exclusion of full-text articles included the following: literature review $(\mathrm{n}=19)$; no treatment outcomes given $(n=14)$; pediatric patients not reported separately $(n=6)$; wrong target population $(n=1)$; small sample size $(\mathrm{n}=19)$; not a full report of a clinical study $(\mathrm{n}=2)$; not relevant to the study question $(\mathrm{n}=3)$; and other $(\mathrm{n}=2)$.

\section{Results}

In general, the methodological quality of the evidence related to this recommendation was poor. The studies that met our inclusion criteria were typically descriptive series of small numbers of patients and were vulnerable to the biases and limitations of a retrospective study design. Because the studies relied on the accuracy and completeness of the medical record, the control of potentially confounding variables was nonexistent. Although most studies did compare outcomes between patient groups treated under alternative management protocols, the rationale behind why a particular treatment was assigned to a particular patient group was not clearly described, leading to significant issues with selection bias. For those studies describing the outcomes of a single management protocol, between-study comparisons of results was hampered by widely disparate management protocols and the use of nonuniform outcome measures (and definitions thereof). These limitations precluded, for the most part, any meaningful quantitative synthesis of the data; what follows is a largely qualitative review of the evidence relevant to this recommendation.

Despite the overall predominance of Class III data, the 13 studies presented in evidentiary Tables $1^{6,17-19,22,27,33}$ and $2^{3,11,12,16,25,32}$ are quite suggestive of the notion that in the management of CSF shunt infection, supplementation of antibiotic treatment with partial (externalization) or complete shunt hardware removal should be considered. Two Class II studies provide particularly compelling evidence in favor of a combined medical and surgical management of CSF shunt infection, and deserve to be elaborated on further.

In 1980, James et al. ${ }^{12}$ published the results of a moderate-quality randomized controlled trial in which 10 patients with evidence of CSF shunt infection were randomized to each of 3 different treatment arms: 1) complete shunt removal, systemic antibiotics, and either external ventricular drainage or ventricular taps for decompression and intrathecal antibiotic administration, with delayed shunt replacement; 2) complete shunt removal and immediate shunt replacement with intrashunt and systemic antibiotics; or 3) intrashunt and systemic antibiotics without shunt removal. The outcome was negative ventricular CSF cultures 48 hours after cessation of antibiotic therapy and again within 4 months of completion of therapy. All 10 patients who underwent complete shunt removal, systemic antibiotics, and either external ventricular drainage or ventricular taps for decompression and intrathecal antibiotic administration were successfully treated. Nine of 10 patients treated with complete shunt removal and immediate shunt replacement with intrashunt and systemic antibiotics achieved therapeutic success. In con- 
TABLE 3: Partial shunt removal and treatment with systemic antibiotics or with systemic and intrathecal antibiotics: summary of evidence

\begin{tabular}{|c|c|c|c|}
\hline Authors \& Year & Study Description & Data Class, Quality, \& Reasons & Results \& Conclusions \\
\hline $\begin{array}{c}\text { James \& Brad- } \\
\text { ley, } 2008^{10}\end{array}$ & $\begin{array}{l}\text { Prospective nonrandomized study of } 2 \text { protocols } \\
\text { for treating complicated shunt infections (multi- } \\
\text { loculated, multiorganism, infection at other site } \\
\text { in body). } \\
\text { Group A, } n=21 \text { treated w/ IV ( } 2 \text { wks) \& IT antibiot- } \\
\text { ics injected through EVD ( }=10) \text { or reservoir } \\
\text { of externalized shunt ( } n=11)(2 \times / \text { wk for } 2 \text { wks). } \\
3 \text { wks of antibiotics in total. Outcome: cure } \\
\text { (cultures } 48 \text { hrs after cessation of antibiotics, at } \\
\text { time of new shunt placement, \& } 3-6 \text { mos later } \\
\text { remained negative). } \\
\text { Group B, } n=18 \text { treated w/ IV ( } 2 \text { wks) \& IT } \\
\text { antibiotics injected through EVD or reservoir of } \\
\text { externalized shunt ( } 1 \times / \text { wk for } 2 \text { wks). } 3 \text { wks of } \\
\text { antibiotics in total. Outcome: cure (cultures } 24 \\
\text { hrs after cessation of antibiotics, at time of new } \\
\text { shunt placement, \& } 3-6 \text { mos later remained } \\
\text { negative). }\end{array}$ & $\begin{array}{l}\text { Class III } \\
\text { Nonrandomized, prospective } \\
\text { case series. } \\
\text { Outcome is different for each } \\
\text { treatment group. }\end{array}$ & $\begin{array}{l}\text { All pts treated according to either protocol } \\
\text { were cured. } \\
\text { Length of stay protocol in Group } A=25.1 \\
\text { days vs protocol in Group } B=19.7 \text { days. } \\
\text { No recurrent shunt infections during the } \\
\text { follow-up period. } \\
\text { Pts w/ complicated shunt infections can be } \\
\text { successfully treated w/ } 2 \text { wks of once } \\
\text { daily IT therapy concurrent w/ } 3 \text { wks of IV } \\
\text { therapy (\& EVD or shunt externalization). }\end{array}$ \\
\hline $\begin{array}{l}\text { Arnell et al., } \\
2007\end{array}$ & $\begin{array}{l}\text { Retrospective review of } 34 \text { consecutively treated } \\
\text { intraventricular shunt infections treated w/ } \\
\text { externalization of the ventricular catheter proxi- } \\
\text { mal to the valve, daily IT injections (generally } \\
\text { guided by CSF antibiotic concentrations, me- } \\
\text { dian } 8 \text { days), \& IV antibiotics (median } 10 \text { days). } \\
\text { Usually no antibiotics after shunt replacement. } \\
\text { Outcome: cure (sterilization of CSF \& resolution of } \\
\text { clinical symptoms). }\end{array}$ & $\begin{array}{l}\text { Class III } \\
\text { Retrospective case series. } \\
\text { No control of confounders. }\end{array}$ & $\begin{array}{l}\text { CSF sterilized in } 1 \text { of } 3,7 \text { of } 8,20 \text { of } 20, \& \\
6 \text { of } 6 \text { cases after } 1,2,3, \&>3 \text { days of } \\
\text { therapy (externalization of ventricular } \\
\text { catheter \& start of IT antibiotics). Clinical } \\
\text { symptoms resolved in parallel w/ the } \\
\text { sterilization of CSF. } \\
\text { Despite the ventricular catheter being left in } \\
\text { place \& the short duration of therapy, the } \\
\text { treatment protocol results in quick CSF } \\
\text { sterilization, a low relapse rate, \& survival } \\
\text { of all pts in this series. }\end{array}$ \\
\hline $\begin{array}{l}\text { Wang et al., } \\
1999\end{array}$ & $\begin{array}{l}23 \text { pts treated according to a documented } \\
\text { management protocol (externalization of distal } \\
\text { catheter unless failure to sterilize CSF, empiric } \\
\text { followed by tailored antibiotics for } 10 \text { days } \\
\text { following sterilization of CSF, reimplantation of } \\
\text { shunt if cultures remain negative for } 3 \text { days off } \\
\text { antibiotics). Comparison group of } 10 \text { historical } \\
\text { controls treated w/ an undisclosed regimen. } \\
\text { Outcome: recurrence (reinfection w/ same organ- } \\
\text { ism w/in } 6 \text { mos). }\end{array}$ & $\begin{array}{l}\text { Class III } \\
\text { Comparative study w/ historical } \\
\text { controls. } \\
\text { No control of confounders. } \\
3 \text { pts had a ventricular reser- } \\
\text { voir only. } \\
\text { Details of treatment of his- } \\
\text { torical control pts not clear } \\
\text { ("duration of antibiotic ther- } \\
\text { apy for each individual case } \\
\text { was decided arbitrarily"). }\end{array}$ & $\begin{array}{l}\text { Reinfection } 0 \text { of } 15 \text { pts treated under proto- } \\
\text { col ( } 8 \text { pts did not require shunt reinser- } \\
\text { tion) vs } 2 \text { of } 10 \text { treated before protocol. } \\
\text { Shorter hospital stay in those treated under } \\
\text { the protocol. } \\
\text { Of those treated under the protocol, pts w/ a } \\
\text { "complex" shunt system required longer } \\
\text { hospitalization. } \\
\text { This treatment protocol may be effective in } \\
\text { the management of shunt infection. }\end{array}$ \\
\hline $\begin{array}{l}\text { Ronan et al., } \\
1995\end{array}$ & $\begin{array}{l}41 \text { episodes of infection in } 39 \text { children treated w/ } \\
\text { antibiotics ( } 28 \text { IV \& oral, } 11 \text { IV + IT + oral, } 4 \text { IT } \\
+ \text { IV, } 1 \text { IT + oral) \& surgical treatment (complete } \\
\text { or partial shunt removal \& immediate or delayed } \\
\text { replacement w/ or w/o external ventricular } \\
\text { drainage). } \\
\text { Outcome: absence of relapse (reinfection w/ } \\
\text { same organism) at } 3 \text { mos, \& was verified by the } \\
\text { absence of relapse for the follow-up period (min } \\
1 \text { year). }\end{array}$ & $\begin{array}{l}\text { Class III } \\
\text { Retrospective case series. } \\
\text { Selection bias. } \\
\text { Overall management approach } \\
\text { too varied to allow for } \\
\text { reasonable conclusions to } \\
\text { be made. }\end{array}$ & $\begin{array}{l}\text { Absence of relapse in } 31 \text { pts, relapse in } 6 \\
\text { pts, death in } 4 \text { pts (not directly related to } \\
\text { shunt infection). } \\
\text { Outcome not dependent on length of antibi- } \\
\text { otic treatment or use of IT antibiotics. } \\
\text { Surgical approach to treatment too varied } \\
\text { to permit conclusions about efficacy. } \\
\text { Complete shunt replacement associated } \\
\text { w/ lower risk of relapse vs partial replace- } \\
\text { ment, \& delayed replacement had better } \\
\text { outcomes vs immediate replacement. }\end{array}$ \\
\hline
\end{tabular}

trast, only 3 of 10 patients who received systemic and intrathecal antibiotics without shunt removal were successfully treated. The treatment results in this latter group rather clearly demonstrate that shunt removal, rather than antibiotic therapy (including intrathecal therapy), was responsible for the improved outcomes seen in the comparison groups. Secondary outcomes also were consistent with a benefit toward surgical removal of the shunt, as length of hospital stay was lowest in those patients who underwent complete shunt removal with delayed shunt re- 
Part 8: Management of CSF shunt infection

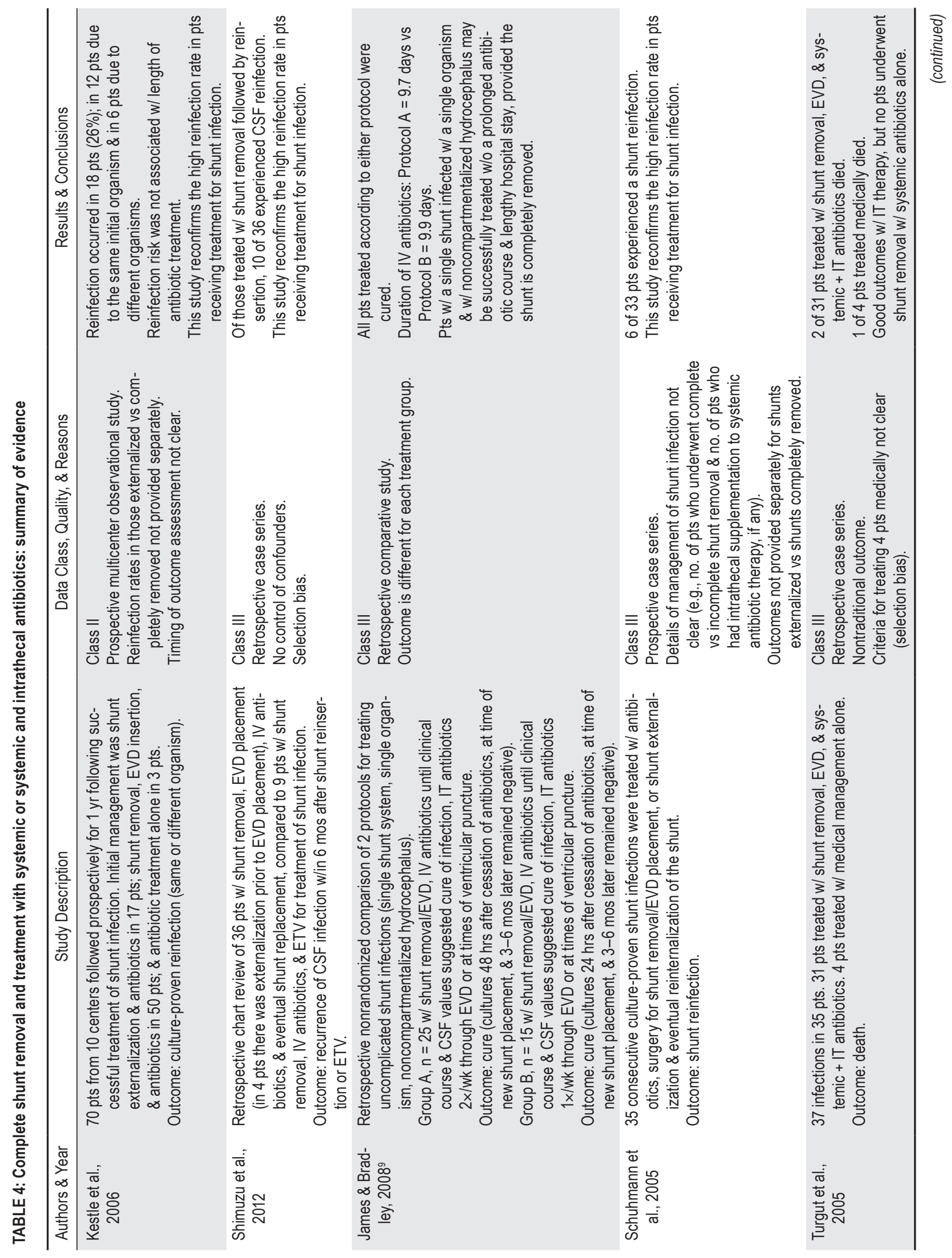


M. S. Tamber et al.

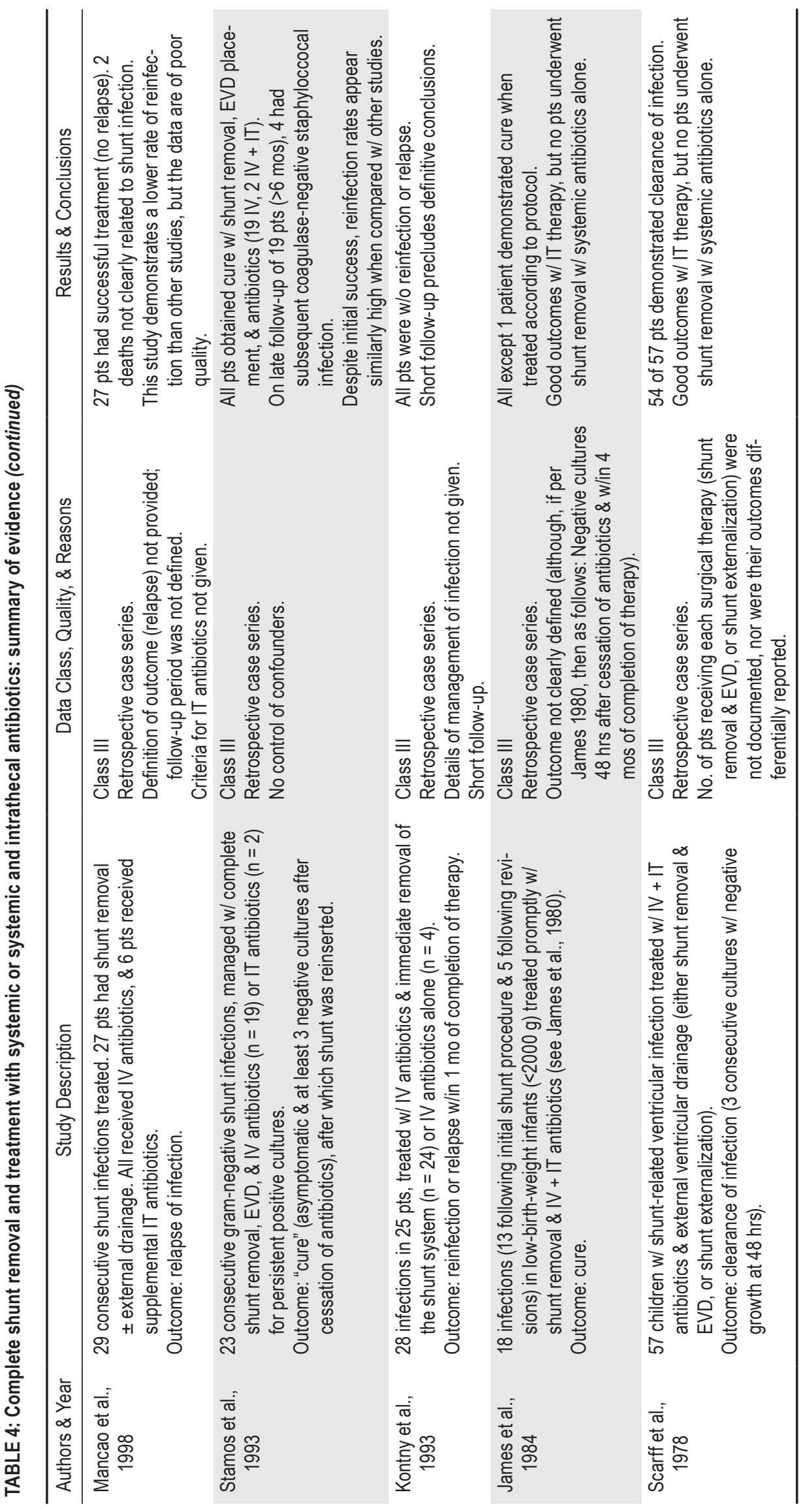


Part 8: Management of CSF shunt infection

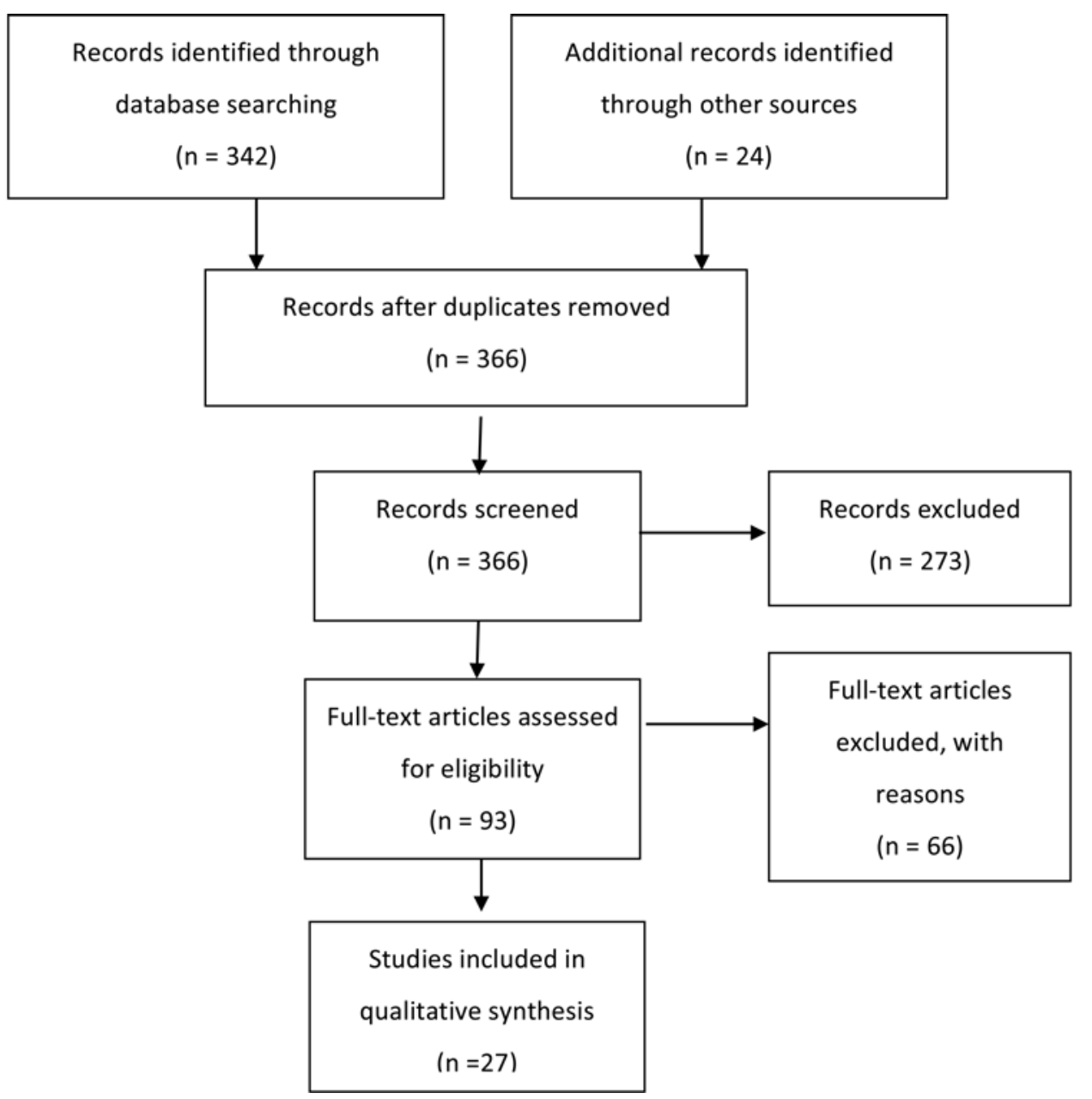

FIG. 2. Flowchart showing the process involved in identifying relevant literature.

placement after a course of systemic and intrathecal antibiotics. The only deaths occurred in those patients who received medical management alone. Because of the convincing inferiority of medical management alone, further randomization to this group was halted, but the study was continued as a prospective nonrandomized comparison of treatment outcomes between those patients receiving intrathecal and systemic antibiotics in conjunction with complete shunt removal and delayed versus immediate shunt replacement. ${ }^{11}$ The principal conclusions remain unchanged.

The nearly equivalent treatment outcomes of shunt removal followed by immediate shunt replacement (that is, shunt replacement in infected CSF) versus delayed shunt replacement (that is, shunt replacement after the CSF has been sterilized) in the aforementioned studies by James and colleagues ${ }^{11,12}$ was suggestive of the potential utility of intrathecal antibiotics in those clinical circumstances in which the shunt must be removed and immediately replaced. As such, these studies provide some evidence applicable to the intrathecal antibiotic recommendation as well. As outlined earlier, it appears that most of the treatment effect comes from shunt removal, making the relative contribution of intrathecal antibiotics to improved outcomes in this scenario rather uncertain. Hence, elevat- ing the recommendation for intrathecal antibiotics to a Level II recommendation, based on these relatively high quality data alone, appears unwarranted.

Additional evidence pertaining to the intrathecal antibiotic recommendation comes largely from Class III studies that examined the results of treatment of ventricular shunt infection in those clinical circumstances in which the infected shunt components are not removed (Table $2^{3,11,12,16,25,32}$ ) or only partially removed (that is, externalized) (Table $3^{2,10,20,34}$ ). There was a Class III study that documented a fairly large proportion of patients who achieved therapeutic success-comparable to the success seen in patients who underwent shunt removal-when the patients were treated with intrathecal antibiotics but their shunts were left in situ. ${ }^{16}$ In addition, Bayston and Rickwood $^{3}$ documented eradication of staphylococcal VA or VP shunt infection in 5 of 43 patients who underwent antibiotic treatment alone; 4 of the 5 patients who were successfully treated received intrathecal antibiotics. In cases in which ventricular shunt infection was treated with systemic and intrathecal antibiotics along with shunt externalization, either because of the complexity of the shunt infection scenario (for example, multiloculated hydrocephalus) or surgeon preference, a prospective nonrandomized study by James and Bradley ${ }^{10}$ and a Class III 
study by Arnell et al. ${ }^{2}$ were both able to demonstrate positive treatment outcomes in all patients in their respective case series. Finally, another retrospective case series by James and Bradley ${ }^{9}$ showed convincingly high cure rates with a significantly shorter length of stay in those patients with an uncomplicated shunt infection (that is, a single shunt system) treated with complete shunt removal together with systemic and intrathecal antibiotics (Table 4). Unfortunately, the absence of a concurrent control group treated with shunt removal and systemic antibiotics alone in this and other studies listed in Table 4 limits the impact of these data to the overall body of evidence.

When examining the studies presented in evidence in Table $3^{2,10,20,34}$ and Table 4, ${ }^{8,9,13-15,21,24,26,30,31}$ it is difficult to say with any degree of clinical certainty whether complete shunt removal leads to better shunt infection treatment outcomes than partial shunt removal. This is due, in part, to the paucity of outcome data comparing the 2 treatment options within the same study population, but also to the confounding effect of intrathecal antibiotic therapy, as described above.

After a full-text review of the contents of papers that were initially identified through our search strategy or our scrutiny of reference lists, predefined criteria led to the exclusion of multiple studies from the evidentiary tables. The recommendations provided above are not materially changed by the exclusion of these studies.

\section{Conclusions}

RECOMMENDATION: Supplementation of antibiotic treatment with partial (externalization) or with complete shunt hardware removal is an option in the management of CSF shunt infection. StRENGTH of ReCommendation: Level II, moderate degree of clinical certainty.

ReCOMmendation: There is insufficient evidence to recommend either shunt externalization or complete shunt removal as a preferred surgical strategy for the management of CSF shunt infection. Therefore, clinical judgment is required. StRength of Recommendation: Level III, unclear degree of clinical certainty.

Recommendation: There is insufficient evidence to recommend the combination of intrathecal and systemic antibiotics for patients with CSF shunt infection in whom the infected shunt hardware cannot be fully removed or must be removed and immediately replaced, or when the CSF shunt infection is caused by specific organisms. The potential neurotoxicity of intrathecal antibiotic therapy may limit its routine use. STRENGTH of ReCOMmendation: Level III, unclear degree of clinical certainty.

It appears that the optimal management of CSF shunt infection requires a multimodality approach. Review and critical appraisal of the available evidence regarding the management of ventricular shunt infection allow for a recommendation for the supplementation of antibiotic treatment with partial (externalization) or complete shunt hardware removal with a moderate degree of clinical certainty. However, a recommendation regarding whether complete shunt removal is favored over partial shunt removal (that is, externalization) cannot be made, owing to severe methodological deficiencies in the exist- ing literature. Furthermore, there is insufficient evidence to recommend the use of intrathecal antibiotic therapy as an adjunct to systemic antibiotic therapy in the management of routine CSF shunt infections, or in other clinical scenarios, such as when an infected CSF shunt cannot be completely removed, must be removed and immediately replaced in the face of ongoing CSF infection, or in the setting of ventricular shunt infection caused by specific organisms (for example, gram-negative bacteria).

Deficiencies in the existing literature regarding the management of CSF shunt infection provide a strong rationale for further prospective research into the subject. Key questions that remain unanswered include, but are certainly not limited to the following:

- Defining the optimal duration of antibiotic therapy in the management of CSF shunt infection, with the aim of simultaneously maximizing the probability of successful treatment without reinfection or relapse, and minimizing the length of hospital stay and overall cost to the health care system.

- Refining the indications for intrathecal antibiotic therapy and ascertaining the risk/benefit profile of such therapy (potential adverse effects vs potential reduction in relapse/reinfection rates and shorter hospital stays).

- Definition and validation of standardized treatment outcome measures, based on microbiological or other biomarker-based criteria. This would not only facilitate a comparison of results across studies, but also potentially yield objective criteria that facilitate decision making in other contentious areas of CSF shunt infection management, such as the optimal timing of shunt reimplantation.

Perhaps the best strategy to treat ventricular shunt infection is to continue our focus on the prevention of this significant complication of CSF shunt therapy.

\section{Acknowledgments}

We acknowledge the American Association of Neurological Surgeons (AANS)/Congress of Neurological Surgeons (CNS) Joint Guidelines Committee for the members' reviews, comments, and suggestions; Laura Mitchell, Guidelines Project Manager for the CNS, for her contributions; Pamela Shaw, research librarian, for her assistance with the literature searches; Kevin Boyer for his assistance with data analysis; and Sue Ann Kawecki for her assistance with editing.

\section{Disclosure}

The systematic review and evidence-based guidelines were funded exclusively by the CNS and AANS Pediatric Section, which received no funding from outside commercial sources to support the development of this document.

Conflict(s) of Interest: None. All members of the Pediatric Hydrocephalus Systematic Review and Evidence-Based Guidelines Task Force declared any potential conflicts of interest prior to beginning work on this evidence review.

Author contributions to the study and manuscript preparation include the following. Conception and design: AANS/CNS Joint Section on Pediatrics. Acquisition of data: all authors. Analysis and interpretation of data: all authors. Drafting the article: Tamber. Critically revising the article: all authors. Reviewed submitted version of 
manuscript: all authors. Approved the final version of the manuscript on behalf of all authors: Flannery. Administrative/technical/material support: all authors. Study supervision: Flannery.

\section{References}

1. Anderson EJ, Yogev R: A rational approach to the management of ventricular shunt infections. Pediatr Infecti Dis J 24:557-558, 2005

2. Arnell K, Enblad P, Wester T, Sjölin J: Treatment of cerebrospinal fluid shunt infections in children using systemic and intraventricular antibiotic therapy in combination with externalization of the ventricular catheter: efficacy in 34 consecutively treated infections. J Neurosurg 107 (3 Suppl):213-219, 2007

3. Bayston R, Rickwood AM: Factors involved in the antibiotic treatment of cerebrospinal fluid shunt infections. $\mathbf{Z}$ Kinderchir 34:339-345, 1981

4. Fan-Havard P, Nahata MC: Treatment and prevention of infections of cerebrospinal fluid shunts. Clin Pharm 6:866-880, 1987

5. Flannery AM, Mitchell L: Pediatric hydrocephalus: systematic literature review and evidence-based guidelines. Part 1: Introduction and methodology. J Neurosurg Pediatr (Suppl) 14:3-7, 2014

6. Forrest DM, Tabara ZB, Towu E, Said AJ: Management of the colonised shunt. Z Kinderchir 42 (Suppl 1):21-22, 1987

7. Gutiérrez-González R, Boto GR, Pérez-Zamarrón A: Cerebrospinal fluid diversion devices and infection. A comprehensive review. Eur J Clin Microbiol Infect Dis 31:889-897, 2012

8. James HE, Bejar R, Gluck L, Coen R, Merritt A, Mannino $\mathrm{F}$, et al: Ventriculoperitoneal shunts in high risk newborns weighing under 2000 grams: a clinical report. Neurosurgery 15:198-202, 1984

9. James HE, Bradley JS: Aggressive management of shunt infection: combined intravenous and intraventricular antibiotic therapy for twelve or less days. Pediatr Neurosurg 44:104111,2008

10. James HE, Bradley JS: Management of complicated shunt infections: a clinical report. J Neurosurg Pediatr 1:223-228, 2008

11. James HE, Walsh JW, Wilson HD, Connor JD: The management of cerebrospinal fluid shunt infections: a clinical experience. Acta Neurochir (Wien) 59:157-166, 1981

12. James HE, Walsh JW, Wilson HD, Connor JD, Bean JR, Tibbs PA: Prospective randomized study of therapy in cerebrospinal fluid shunt infection. Neurosurgery 7:459-463, 1980

13. Kestle JR, Garton HJ, Whitehead WE, Drake JM, Kulkarni AV, Cochrane DD, et al: Management of shunt infections: a multicenter pilot study. J Neurosurg 105 (3 Suppl):177-181, 2006

14. Kontny U, Höfling B, Gutjahr P, Voth D, Schwarz M, Schmitt HJ: CSF shunt infections in children. Infection 21:89-92, 1993

15. Mancao M, Miller C, Cochrane B, Hoff C, Sauter K, Weber E: Cerebrospinal fluid shunt infections in infants and children in Mobile, Alabama. Acta Paediatr 87:667-670, 1998

16. McLaurin RL: Treatment of infected ventricular shunts. Childs Brain 1:306-310, 1975

17. Morrice JJ, Young DG: Bacterial colonisation of Holter valves: a ten-year survey. Dev Med Child Neurol 16 (6 Suppl 32):85-90, 1974

18. Nicholas JL, Kamal IM, Eckstein HB: Immediate shunt replacement in the treatment of bacterial colonisation of Holter valves. Dev Med Child Neurol 12 (Suppl 22):110-113, 1970

19. Odio C, McCracken GH Jr, Nelson JD: CSF shunt infections in pediatrics. A seven-year experience. Am J Dis Child 138: 1103-1108, 1984

20. Ronan A, Hogg GG, Klug GL: Cerebrospinal fluid shunt infections in children. Pediatr Infect Dis J 14:782-786, 1995
21. Scarff TB, Nelson PB, Reigel DH: External drainage for ventricular infection following cerebrospinal fluid shunts. Childs Brain 4:129-136, 1978

22. Schoenbaum SC, Gardner P, Shillito J: Infections of cerebrospinal fluid shunts: epidemiology, clinical manifestations, and therapy. J Infect Dis 131:543-552, 1975

23. Schreffler RT, Schreffler AJ, Wittler RR: Treatment of cerebrospinal fluid shunt infections: a decision analysis. Pediatr Infect Dis J 21:632-636, 2002

24. Schuhmann MU, Ostrowski KR, Draper EJ, Chu JW, Ham $\mathrm{SD}$, Sood S, et al: The value of C-reactive protein in the management of shunt infections. J Neurosurg 103 (3 Suppl): 223-230, 2005

25. Sells CJ, Shurtleff DB, Loeser JD: Gram-negative cerebrospinal fluid shunt-associated infections. Pediatrics 59:614-618, 1977

26. Shimizu T, Luciano MG, Fukuhara T: Role of endoscopic third ventriculostomy at infected cerebrospinal fluid shunt removal. Clinical article. J Neurosurg Pediatr 9:320-326, 2012

27. Shurtleff DB, Foltz EL, Weeks RD, Loeser J: Therapy of Staphylococcus epidermidis: infections associated with cerebrospinal fluid shunts. Pediatrics 53:55-62, 1974

28. Simon TD, Hall M, Riva-Cambrin J, Albert JE, Jeffries HE, Lafleur B, et al: Infection rates following initial cerebrospinal fluid shunt placement across pediatric hospitals in the United States. Clinical article. J Neurosurg Pediatr 4:156-165, 2009

29. Simon TD, Riva-Cambrin J, Srivastava R, Bratton SL, Dean JM, Kestle JR: Hospital care for children with hydrocephalus in the United States: utilization, charges, comorbidities, and deaths. J Neurosurg Pediatr 1:131-137, 2008

30. Stamos JK, Kaufman BA, Yogev R: Ventriculoperitoneal shunt infections with gram-negative bacteria. Neurosurgery 33:858-862, 1993

31. Turgut M, Alabaz D, Erbey F, Kocabas E, Erman T, Alhan E, et al: Cerebrospinal fluid shunt infections in children. Pediatr Neurosurg 41:131-136, 2005

32. Wald SL, McLaurin RL: Cerebrospinal fluid antibiotic levels during treatment of shunt infections. J Neurosurg 52:41-46, 1980

33. Walters BC, Hoffman HJ, Hendrick EB, Humphreys RP: Cerebrospinal fluid shunt infection. Influences on initial management and subsequent outcome. J Neurosurg 60:1014-1021, 1984

34. Wang KC, Lee HJ, Sung JN, Cho BK: Cerebrospinal fluid shunt infection in children: efficiency of management proto$\mathrm{col}$, rate of persistent shunt colonization, and significance of 'off-antibiotics' trial. Childs Nerv Syst 15:38-44, 1999

35. Whitehead WE, Kestle JR: The treatment of cerebrospinal fluid shunt infections. Results from a practice survey of the American Society of Pediatric Neurosurgeons. Pediatr Neurosurg 35:205-210, 2001

36. Working Party on the Use of Antibiotics in Neurosurgery of the British Society for Antimicrobial Chemotherapy: Treatment of infections associated with shunting for hydrocephalus. Br J Hosp Med 53:368-373, 1995

37. Yogev R: Cerebrospinal fluid shunt infections: a personal view. Pediatr Infect Dis 4:113-118, 1985

Manuscript submitted June 25, 2014.

Accepted July 7, 2014.

Please include this information when citing this paper: DOI: 10.3171/2014.7.PEDS14328.

Address correspondence to: Ann Marie Flannery, M.D., Department of Neurological Surgery, Saint Louis University, 3565 Vista Ave., St. Louis, MO 63110. email: flanneam@slu.edu. 